\title{
k-Super Mean Labeling of Some Graphs
}

\author{
Dr. M. Tamilselvi ${ }^{1}$, K. Akilandeswari ${ }^{2}$, V. Suguna ${ }^{3}$ \\ ${ }^{1}$ Associate Professor, Department of Mathematics, SeethalakshmiRamaswami College, Tirchirappalli - 620002 \\ ${ }^{2,3}$ Research Scholar, Department of Mathematics, SeethalakshmiRamaswami College, Tirchirappalli - 620002
}

\begin{abstract}
Let $G$ be a $(p, q)$ graph and $f: V(G) \rightarrow\{1,2,3, \ldots, p+q\}$ be an injection. For each edge e $=u v$, let $f^{*}(e)=\frac{f(u)+f(v)}{2}$ if $f(u)+f(v)$ is even and $f^{*}(e)=\frac{f(u)+f(v)+1}{2}$ if $f(u)+f(v)$ is odd, then $f$ is called super mean labeling if $f(V) \cup\left\{f^{*}(e): e \in E(G)\right\}=$ $\{1,2,3, \ldots, p+q\}$. A graph that admits a super mean labeling is called Super mean graph. Let $G$ be $a \quad(p, q)$ graph and $f: V(G) \rightarrow$ $\{k, k+1, k+2, \ldots, p+q+k-1\}$ be an injection. For each edge e $=u v$, let $f^{*}(e)=\frac{f(u)+f(v)}{2}$ if $f(u)+f(v)$ is even and $f^{*}(e)=$ $\frac{f(u)+f(v)+1}{2}$ if $f(u)+f(v)$ is odd, then $f$ is called $k$ - super mean labeling if $f(V) \cup\left\{f^{*}(e): e \in E(G)\right\}=\{k, k+1, \ldots, p+q+k-1\} . A$ graph that admits a $k$-super mean labeling is called $k$-Super mean graph. In this paper we investigate $k-$ super mean labeling of $<B_{n, n}$, $w>, S\left(B_{n, n}\right)$, and $T_{n} \odot K_{1}$.
\end{abstract}

Keywords: Super mean labeling, Super mean graph,k-Super mean labeling, k-Super mean graph, Bistar graphs, $T_{n} \odot K_{1}$.

\section{Introduction}

All graphs in this paper are finite, simple and undirected. Terms not defined here are used in the sense of Harary [7]. The symbols $\mathrm{V}(\mathrm{G})$ and $\mathrm{E}(\mathrm{G})$ will denote the vertex set and edge set of a graph $\mathrm{G}$.

Graph labeling was first introduced in the late 1960's. Many studies in graph labeling refer to Rosa's research in 1967 [11]. Labeled graphs serve as useful models for a broad range of applications such as X-ray, crystallography, radar, coding theory, astronomy, circuit design and communication network addressing. Particularly interesting applications of graph labeling can be found in [1-4].

The concept of mean labeling was introduced and studied by S. Somasundaram and R.Ponraj [12].

The concept of super mean labeling was introduced and studied by D. Ramya et al. [11]. Futher some results on super mean graphs are discussed in $[8,9,10,13,15]$.

B. Gayathri and M. Tamilselvi [5-6, 14] extended super mean labeling to $\mathrm{k}$-super mean labeling.

In this paper we investigate $\mathrm{k}$ - Super mean labeling of Bistar graphs and $\mathrm{T}_{\mathrm{n}} \odot \mathrm{K}_{1}$. For brevity, we use k-SML for k-super mean labeling.

\section{Definition1.1}

Let $\mathrm{G}$ be a $(\mathrm{p}, \mathrm{q})$ graph and $f: V(G) \rightarrow\{1,2,3, \ldots, p+q\}$ be an injection. For each edge e $=u v$, let $f^{*}(e)=\frac{f(u)+f(v)}{2}$ if $f(u)+f(v)$ is even and $f^{*}(e)=\frac{f(u)+f(v)+1}{2}$ if

$f(u)+f(v)$ is odd, then $\mathrm{f}$ is called Super mean labeling if $f(V) \cup\left\{f^{*}(e): e \in E(G)\right\}=\{1,2,3, \ldots, p+q\}$. A graph that admits a super mean labeling is called Super mean graph.

\section{Definition1.2}

Let $\mathrm{G}$ be a $(\mathrm{p}, \mathrm{q})$ graph and $f: V(G) \rightarrow\{k, k+1, k+2, \ldots, p+q+k-1\}$ be an injection. For each edge e $=$ uv, let $f^{*}(e)=\frac{f(u)+f(v)}{2}$ if $f(u)+f(v)$ is even and $f^{*}(e)=\frac{f(u)+f(v)+1}{2}$ if

$f(u)+f(v)$ is odd, then $\mathrm{f}$ is called k-Super mean labeling if $f(V) \cup\left\{f^{*}(e): e \in E(G)\right\}=\{k, k+1, \ldots, p+q+k-1\}$. A graph that admits a k-super mean labeling is called k-Super mean graph.

\section{Definition1.3}

A bistar $\left(B_{n, n}\right)$ is the graph obtained by joining the central vertices of two copies of star $K_{1, n}$ by an edge.

\section{Definition1.4}

If $\mathrm{G}$ is a graph, then $\mathrm{S}(\mathrm{G})$ is a graph obtained by subdividing each edge of $\mathrm{G}$ by a vertex.

\section{Definition1.5}

A triangular snake $\left(T_{n}\right)$ is obtained from a path by identifying each edge of the path with an edge of the cycle $\mathrm{C}_{3}$.

\section{Main Results}

\section{Definition 2.1}

The graph $<\mathrm{B}_{\mathrm{n}, \mathrm{n}}$, w $>$ is the graph obtained by subdividing the central edge of the bistar $B_{n, n}$ with the vertex $w$.

\section{Theorem 2.2}

The graph $<\mathrm{B}_{\mathrm{n}, \mathrm{n}}, \mathrm{w}>$ is a k-super mean graph for all $\mathrm{n} \geq 2$.

$$
\begin{aligned}
& \text { Proof } \\
& \text { Let } \mathrm{V}\left(<\mathrm{B}_{\mathrm{n}, \mathrm{n}}, \mathrm{w}>\right)=\left\{\mathrm{u}, \mathrm{v}, \mathrm{w}, \mathrm{u}_{\mathrm{i}}, \mathrm{v}_{\mathrm{i}} ; 1 \leq \mathrm{i} \leq \mathrm{n}\right\} \text { and } \\
& \mathrm{E}\left(<\mathrm{B}_{\mathrm{n}, \mathrm{n}}, \mathrm{w}>\right)=\{\mathrm{e}=(\mathrm{u}, \mathrm{w})\} \mathrm{U} \\
& \left\{\mathrm{e}^{\prime \prime}=(\mathrm{w}, \mathrm{v})\right\} \mathrm{U} \\
& \left\{\mathrm{e}_{\mathrm{i}}=\left(\mathrm{u}, \mathrm{u}_{\mathrm{i}}\right): 1 \leq \mathrm{i} \leq \mathrm{n}\right\} \mathrm{U} \\
& \left\{\mathrm{e}_{\mathrm{i}}^{\prime}=\left(\mathrm{v}, \mathrm{v}_{\mathrm{i}}\right): 1 \leq \mathrm{i} \leq \mathrm{n}\right\}
\end{aligned}
$$

be the vertices and edges of $<B_{n, n}$, $w>$ respectively.

Case (i): $\boldsymbol{n}$ is even

Let $\mathrm{n}=2 l$, for some $l$.

\section{Volume 5 Issue 6, June 2016}


Define

$f: V\left(<B_{n, n}, w>\right) \rightarrow\{k, k+1, k+2, \ldots, 4 n+k+5\}$ by

$f(u)=k$,

$f(w)=4 n+k+4$

$f(v)=4 n+k+2$

$f\left(u_{i}\right)=4 i+k-2 ;$ if $1 \leq i \leq 2 l$ and if $i \neq l+1$,

$f\left(u_{l+1}\right)=4 l+k+1$,

$f\left(v_{i}\right)=4 i+k ;$ if $1 \leq i \leq 2 l$.

Now the induced edge labels are

$f^{*}(e)=2 n+k+2$,

$f^{*}\left(e^{\prime \prime}\right)=4 n+k+3$,

$f^{*}\left(e_{i}\right)=2 i+k-1 ; 1 \leq i \leq n$,

$f^{*}\left(e_{1}^{\prime}\right)=f^{*}\left(e_{n}\right)+4$

$f^{*}\left(e_{i}^{\prime}\right)=f^{*}\left(e_{1}^{\prime}\right)+2(i-1) ; 2 \leq i \leq n$.

Here $\mathrm{p}=2 \mathrm{n}+3, \mathrm{q}=2 \mathrm{n}+2$.

Clearly, $f(V) \cup\left\{f^{*}(e): e \in E\left(<B_{n, n}, w>\right)\right\}=$

$$
\{k, k+1, \ldots, 4 n+k+4\} \text {. }
$$

So $\mathrm{f}$ is a $\mathrm{k}$ - super mean labeling, when $\mathrm{n}$ is even.

Hence $<B_{n, n}, w>$ is a $\mathrm{k}$-super mean graph, when $\mathrm{n}$ is even.

Case (ii): $\mathbf{n}$ is odd

Then $\mathrm{n}=2 l+1$, for some $l$.

We label the vertices of $\left\langle B_{n, n}, w\right\rangle$ as follows:

$f(u)=k$,

$f(w)=4 n+k+4$

$f(v)=4 n+k+2$,

$f\left(u_{i}\right)=4 i+k-2$; if $1 \leq i \leq 2 l+1$,

$f\left(v_{i}\right)=4 i+k ;$ if $1 \leq i \leq 2 l+1$ and if $i \neq l+1$,

$f\left(v_{l+1}\right)=4 l+k+3$.

Now the induced edge labels are

$f^{*}(e)=2 n+k+2$,

$f^{*}\left(e^{\prime \prime}\right)=4 n+k+3$,

$f^{*}\left(e_{i}\right)=2 i+k-1 ;$ if $1 \leq i \leq n$

$f^{*}\left(e_{1}^{\prime}\right)=f^{*}\left(e_{n}\right)+4$,

$f^{*}\left(e_{i}\right)=f^{*}\left(e_{1}^{\prime}\right)+2(i-1) ; 2 \leq i \leq n$.

Here $\mathrm{p}=2 \mathrm{n}+3, \mathrm{q}=2 \mathrm{n}+2$.

Clearly, $f(V) \cup\left\{f^{*}(e): e \in E\left(<B_{n, n}, w>\right)\right\}=$

$$
\{k, k+1, \ldots, 4 n+k+4\} \text {. }
$$

So $\mathrm{f}$ is a $\mathrm{k}$ - super mean labeling, when $\mathrm{n}$ is odd.

Hence $\left\langle B_{n, n}, w\right\rangle$ is a $\mathrm{k}$ - super mean graph, when $\mathrm{n}$ is odd.

\section{Example 2.3}

50 - Super mean graph of $\left\langle\mathrm{B}_{2,2}, \mathrm{w}\right\rangle$ is given in figure 2.1:

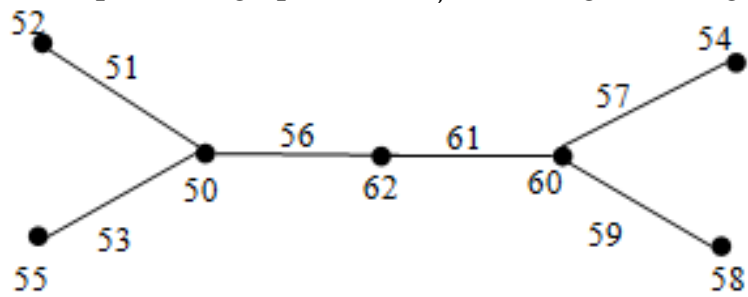

Figure 2.1: 50-SML of $\left\langle B_{2,2}, \mathrm{w}\right\rangle$

Example 2.4

50 - Super mean graph of $\left.<\mathrm{B}_{3,3}, \mathrm{w}\right\rangle$ is given in figure 2.2:

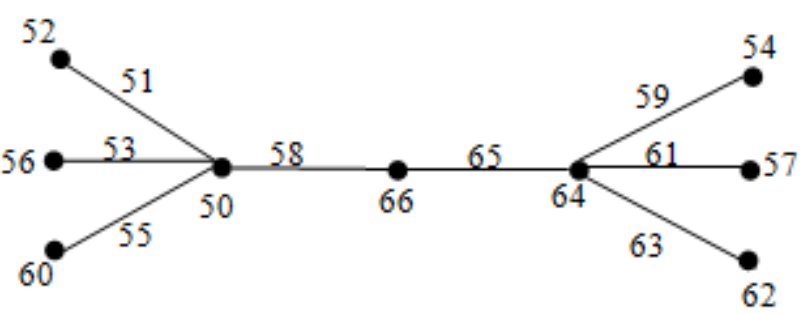

Figure 2.2: 50-SML of $\left\langle B_{3,3}, \mathrm{w}\right\rangle$

\section{Theorem 2.5}

The graph $S\left(B_{n, n}\right)$ is a k-Super mean graph for all $n \geq 2$.

Proof

$\operatorname{Let} V\left(S\left(B_{n, n}\right)\right)=\left\{u, v, w, u_{i}, v_{i}, u_{i}^{\prime}, v_{i}^{\prime} ; 1 \leq i \leq n\right\}$ and $E\left(S\left(B_{n, n}\right)\right)=\{e=(w, v)\} \cup$

$$
\begin{aligned}
& \left\{e_{i}=\left(u, u_{i}\right) ; 1 \leq i \leq n\right\} \cup \\
& \left\{e_{n+1}=(u, w)\right\} \cup \\
& \left\{e_{j}=\left(v, v_{i}\right) ; 1 \leq i \leq n, n+2 \leq j \leq 2 n+1\right\} \cup \\
& \left\{e_{i_{i \prime}^{\prime}}^{\prime}=\left(u_{i}, u_{i}^{\prime}\right): 1 \leq i \leq n\right\} \cup \\
& \left\{e_{i}^{\prime}=\left(v_{i}, v_{i}^{\prime}\right): 1 \leq i \leq n\right\}
\end{aligned}
$$

be the vertices and edges of $S\left(B_{n, n}\right)$ respectively.

Define

$f: V\left(S\left(B_{n, n}\right)\right) \rightarrow\{k, k+1, k+2, \ldots, 8 n+k+4\}$ by

$f(u)=k$,

$f(w)=8 n+k+4$

$f(v)=8 n+k+2$

$f\left(u_{i}\right)=8 i+k-4 ; 1 \leq i \leq n$,

$f\left(u_{i}^{\prime}\right)=8 i+k-6 ; 1 \leq i \leq n$,

$f\left(v_{i}\right)=8 i+k-2 ; 1 \leq i \leq n$,

$f\left(v_{i}\right)=8 i+k ; 1 \leq i \leq n$.

Now the induced edge labels are

$f^{*}(e)=8 n+k+3$,

$f^{*}\left(e_{i}\right)=4 i+k-3 ; 1 \leq i \leq 2 n+1$,

$f^{*}\left(e_{i}^{\prime}\right)=8 i+k-5 ; 1 \leq i \leq n$,

$f^{*}\left(e_{i}^{\prime \prime}\right)=8 i+k-1 ; 1 \leq i \leq n$.

Here $\mathrm{p}=4 \mathrm{n}+3, \mathrm{q}=4 \mathrm{n}+2$.

Clearly, $f(V) \cup\left\{f^{*}(e): e \in E\left(S\left(B_{n, n}\right)\right)\right\}=$

$$
\{k, k+1, \ldots, 8 n+k+4\} \text {. }
$$

So $\mathrm{f}$ is a $\mathrm{k}$ - super mean labeling.

Hence $S\left(B_{n, n}\right)$ is a $\mathrm{k}$ - super mean graphfor $n \geq 2$.

\section{Example 2.6}

25-Super mean labeling of $S\left(B_{5,5}\right)$ is given in figure2.3:

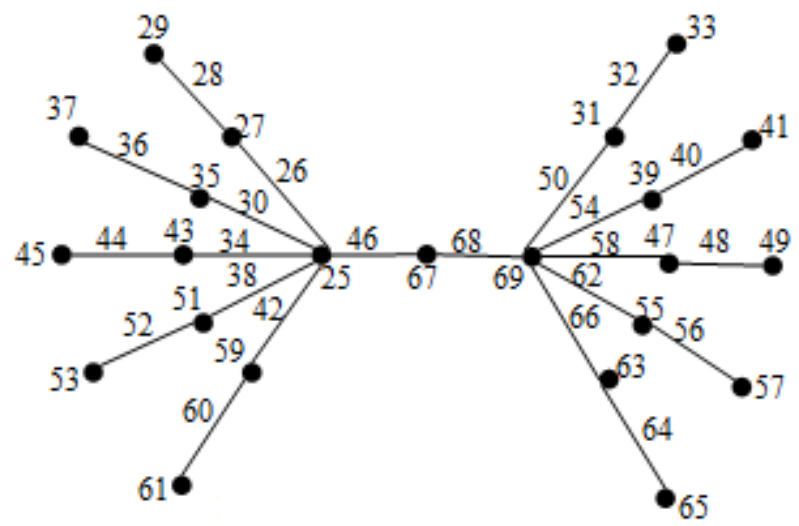

Figure 2.3: 25- SML of $\mathrm{S}\left(\mathrm{B}_{5,5}\right)$

\section{Volume 5 Issue 6, June 2016} www.ijsr.net 


\section{International Journal of Science and Research (IJSR) \\ ISSN (Online): 2319-7064}

Index Copernicus Value (2013): 6.14 | Impact Factor (2015): 6.391

Theorem 2.7

The graph $T_{n} \odot K_{1}$ is a k-Super mean graph, for $n \geq 2$.

$$
\begin{aligned}
& \text { Proof: } \\
& \begin{aligned}
\operatorname{Let} V\left(T_{n} \odot K_{1}\right)= & \left\{u_{i}, u_{i}^{\prime}, ; 1 \leq i \leq n-1\right\} \cup \\
& \left\{v_{i}, v_{i}^{\prime} ; 1 \leq i \leq n\right\} \text { and }
\end{aligned} \\
& \qquad \begin{aligned}
E\left(T_{n} \odot K_{1}\right)= & \left\{e_{i}=\left(u_{i}, u_{i}^{\prime}\right) ; 1 \leq i \leq n-1\right\} \cup \\
& \left\{e_{i}^{\prime}=\left(v_{i}, u_{i}\right): 1 \leq i \leq n-1\right\} \cup \\
& \left\{e_{i^{\prime \prime}}=\left(v_{i+1}, u_{i}^{\prime}\right): 1 \leq i \leq n-1\right\} \cup \\
& \left\{e_{i}^{\prime \prime \prime}=\left(v_{i}, v_{i+1}\right): 1 \leq i \leq n-1\right\} \cup \\
& \left\{e_{i}^{i v}=\left(v_{i}, v_{i}^{\prime}\right): 1 \leq i \leq n\right\}
\end{aligned}
\end{aligned}
$$

be the vertices and edges of $T_{n} \odot K_{1}$ respectively.

Define

$f: V\left(T_{n} \odot K_{1}\right) \rightarrow\{k, k+1, k+2, \ldots, 9 n+k-7\}$ by

$f\left(u_{i}\right)=9 i+k-3 ; 1 \leq i \leq n-1$,

$f\left(u_{i}\right)=9 i+k-5 ; 1 \leq i \leq n-1$,

$f\left(v_{i}\right)=9 i+k-7 ; 1 \leq i \leq n$,

$f\left(v_{i}^{\prime}\right)=9 i++9 k ; 1 \leq i \leq n$.

Now the induced edge labels are

$f^{*}\left(e_{i}\right)=9 i+k-4 ; 1 \leq i \leq n-1$,

$f\left(e_{i}^{\prime}\right)=9 i+k-6 ; 1 \leq i \leq n-1$,

$f\left(e_{i}^{\prime \prime}\right)=9 i+k-1 ; 1 \leq i \leq n-1$,

$f\left(e_{i}^{\prime \prime \prime}\right)=9 i+k-2 ; 1 \leq i \leq n-1$,

$f\left(e_{i}^{i v}\right)=9 i+k-8 ; 1 \leq i \leq n$.

Here $\mathrm{p}=4 \mathrm{n}-2, \mathrm{q}=5 \mathrm{n}-4$.

Clearly, $f(V) \cup\left\{f^{*}(e): e \in E\left(T_{n} \odot K_{1}\right)\right\}=$

So $\mathrm{f}$ is a $\mathrm{k}$ - super mean labeling.

$$
\{k, k+1, \ldots, 9 n+k-7\} \text {. }
$$

Hence $_{n} \odot K_{1}$ is a k - super mean graph.

\section{Example 2.8}

50-Super mean labeling of $\mathrm{T}_{4} \odot \mathrm{K}_{1}$ is given in figure 2.4:

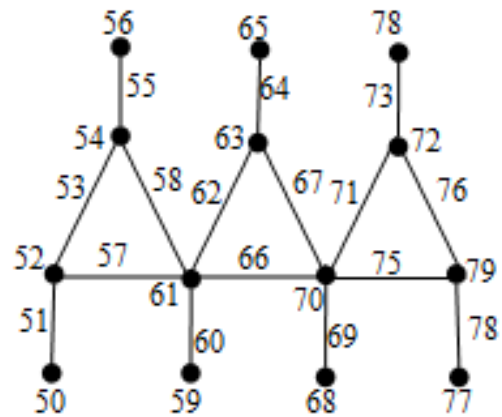

Figure 2.6: 50-SMLof $\mathrm{T}_{4} \odot \mathrm{K}_{1}$
[6] B. Gayathri and M. Tamilselvi, k-super mean labeling of some trees and cycle related graphs, Bulletin of Pure and Applied Sciences, Volume 26E(2) (2007) 303-311.

[7] F. Harary, Graph Theory, Addison Wesley, Massachusetts (1972).

[8] P. Jeyanthi and D. Ramya, Super mean labeling of some classes of graphs, International J. Math. Combin., 1 (2012) 83-91.

[9] P. Jeyanthi, D. Ramya and P. Thangavelu, On super mean graphs, AKCE J. Graphs Combin., 6 No. 1 (2009) 103-112.

[10] D. Ramya, R. Ponraj and P. Jeyanthi, Super mean labeling of graphs, ArsCombin., 112 (2013) 65-72.

[11] Rosa, On certain valuations of the vertices of a graph Theory of Graphs (Internet Symposium, Rome, July (1966), Gordon and Breach, N.Y. and Duhod, Paris (1967) 349-355.

[12] S. Somasundaram and R. Ponraj, Mean labeling of graphs, National Academy Science Letter, 26 (2003), 210-213.

[13] P.Sugirtha, R. Vasuki and J. Venkateswari, Some new super mean graphs, International Journal of Mathematics Trends and Technology, Vol. 19 No. 1 March 2015.

[14] M. Tamilselvi, A study in Graph TheoryGeneralization of super mean labeling, Ph.D. Thesis, Vinayaka Mission University, Salem, August (2011).

[15] R. Vasuki and A. Nagarajan, Some results on super mean graphs, International J. Math. Combin., 3 (2009) $82-96$.

\section{References}

[1] G.S. Bloom, S.W. Golomb, Applications of numbered undirected graphs, Proc. IEEE, 65 (1977), 562-570.

[2] G.S. Bloom, S.W. Golomb, Numbered complete graphs unusual rulers and assorted applications, Theory and Applications of Graphs-Lecture notes in Math., Springer Verlag, New York, 642 (1978), 53-65.

[3] G.S. Bloom, D.F. Hsu, On graceful digraphs and a problem in network addressing, CongressusNumerantium, 35 (1982) 91-103.

[4] J.A. Gallian, A dynamic survey of graph labeling, Electronic Journal of Combinatorics, 18 (2015) \# DS6.

[5] B. Gayathri, M. Tamilselvi, M. Duraisamy, k-super mean labeling of graphs, In: Proceedings of the International Conference on Mathematicsand Computer Sciences, Loyola College, Chennai (2008), 107-111.

\section{Volume 5 Issue 6, June 2016} www.ijsr.net 